\title{
Flame ionization detection for the determination of the chemical composition distribution of non-UV absorbing copolymers
}

Citation for published version (APA):

van Doremaele, G. H. J., Kurja, J., Claessens, H. A., \& German, A. L. (1991). Flame ionization detection for the determination of the chemical composition distribution of non-UV absorbing copolymers. Chromatographia, 31(910), 493-499. https://doi.org/10.1007/BF02262395

DOI:

10.1007/BF02262395

Document status and date:

Published: 01/01/1991

Document Version:

Publisher's PDF, also known as Version of Record (includes final page, issue and volume numbers)

Please check the document version of this publication:

- A submitted manuscript is the version of the article upon submission and before peer-review. There can be important differences between the submitted version and the official published version of record. People interested in the research are advised to contact the author for the final version of the publication, or visit the DOI to the publisher's website.

- The final author version and the galley proof are versions of the publication after peer review.

- The final published version features the final layout of the paper including the volume, issue and page numbers.

Link to publication

\footnotetext{
General rights

- You may freely distribute the URL identifying the publication in the public portal. follow below link for the End User Agreement:

www.tue.nl/taverne

\section{Take down policy}

If you believe that this document breaches copyright please contact us at:

openaccess@tue.nl

providing details and we will investigate your claim.
}

Copyright and moral rights for the publications made accessible in the public portal are retained by the authors and/or other copyright owners and it is a condition of accessing publications that users recognise and abide by the legal requirements associated with these rights.

- Users may download and print one copy of any publication from the public portal for the purpose of private study or research.

- You may not further distribute the material or use it for any profit-making activity or commercial gain

If the publication is distributed under the terms of Article $25 \mathrm{fa}$ of the Dutch Copyright Act, indicated by the "Taverne" license above, please 


\title{
Flame Ionization Detection for the Determination of the Chemical Composition Distribution of Non-UV Absorbing Copolymers
}

\author{
G. H. J. van Doremaele ${ }^{1} /$ J. Kurja ${ }^{1} /$ H. A. Claessens*2/ A. L. German ${ }^{1}$ \\ ${ }^{1}$ Laboratory of Polymer Chemistry and Technology, Department of Chemistry, Eindhoven University of Technology, \\ P.O.Box 513, $6500 \mathrm{MB}$ Eindhoven, The Netherlands. \\ ${ }^{2}$ Laboratory of Instrumental Analysis, Department of Chemistry, Eindhoven University of Technology, P.O.Box 513, 5600 \\ MB Eindhoven, The Netherlands.
}

\section{Key Words \\ Column liquid chromatography \\ Flame ionization detection \\ Poly(styrene-co-methyl acrylate) \\ Poly(methyl acrylate-co- $n$-butyl acrylate) \\ Chemical composition distribution}

\begin{abstract}
Summary
This investigation is focused on the development of HPLC with subsequent flame ionization detection as a tool to determine the chemical composition distribution of non- or poorly UV absorbing copolymers. Experiments were carried out with poly(styrene-co-methyl acrylate) and poly(methyl acrylate-co- $n$-butyl acrylate) copolymers. HPLC combined with FID provided useful qualitative information. Quantitative information could be obtained after calibration.
\end{abstract}

\section{Introduction}

It is generally recognized that the chemical composition distribution (CCD) of a specific copolymer is one of the important factors determining its final product properties. Many investigations have been devoted to developing methods for the accurate determination of the CCD. Nowadays, in principal, quantitative information can be provided by gradient thin layer chromatography (TLC) in combination with Flame Ionization Detection (TLC/FID) [1]. This technique has been investigated for e.g. poly(styreneco-acrylonitrile) and several styrene-methacrylate copolymers [2-7]. More recently the most widely investigated method for the determination of CCDs is gradient HighPerformance Liquid Chromatography (HPLC) [8-11]. In the separation of copolymers with gradient elution, precipitation and/or adsorption-desorption mechanisms play a dominant role. A sufficient difference in polarity of both the different monomeric units of a specific copolymer is a prerequisite for a successful separation. The main advan- tages of HPLC compared to TLC are the improved separation efficiency and reproducibility.

Gradient HPLC is in many cases performed in combination with a UV detector, which is suitable for many compounds. However, this is a limitation in some cases, for instance in poly(co-methacrylate) and poly(styrene-co-methacrylate), the methacrylate monomeric units can hardly be detected, because the extinction coefficient of the ester groups it too low. In the case of poly(styrene-co-methacrylate) the detection is generally carried out with UV detection at 254 $260 \mathrm{~nm}$. This results in serious detection problems in the methacrylate-rich copolymers. In order to overcome this problem, alternative detection methods have been studied. One possibility is to use an evaporative light-scattering mass detector [12-15]. The eluent together with the (co)polymer is evaporated in air and the polymer particles so formed are subsequently detected by light scattering. These detectors are not straightforward, since the particle size distribution (PSD) produced by the nebulizer depends on the (co)polymer composition and eluent composition and the PSD strongly influences the detector response.

Another possibility is to use a moving belt flame ionization detector [16-18]. Here, the column effluent is sprayed onto a transport device, for example a moving quartz fibre, placed around a wheel, rotating in a heated housing. Subsequently, the solvent is evaporated by heating. The nonvolatile solutes, i.e. (co)polymers, retained on the fibre can be detected by an FID. Compared to UV-detectors, FID detectors are more sensitive and suitable for the detection of copolymers which contain few or even non UV chromophores like, for instance, the methacrylate-rich copolymers. This paper describes an investigation of the feasibility of using HPLC combined with FID detection (LC/FID) to determine the CCD of poly(styrene-co-methyl acrylate) and poly(methyl acrylate-co- $n$-butyl acrylate).

Batch emulsion copolymers of styrene and methyl acrylate are known to often exhibit a bimodal CCD with one peak representing real copolymer molecules and another peak representing polymethyl acrylate $[7,19]$, which cannot be detected by means of a UV detector. This bimodality is caused by a strong composition drift during the emulsion copolymerization process. 


\section{Experimental}

\section{HPLC Equipment and Solvents}

Gradient elution was performed with a system controller (Model 720) and two HPLC pumps (Model 510, MilliporeWaters Corp., Milford, MA, USA). A Waters Intelligent Sample Processor (Wisp) (Model 710) was used to inject 1$100 \mu \mathrm{L}$ samples. A Waters Multi-wavelength Detector, Model 490, (operating at 260 and/or $235 \mathrm{~nm}$ ) and a TRACOR model 945 LC/FID moving braid flame ionization detector were installed in series to monitor the eluent from the column.

HPLC solvents. Methanol (HPLC-grade) was obtained from Aldrich Chemicals (Brussels, Belgium). Dichloromethane (DCM) and n-heptane were from Merck (Darmstadt, FRG). n-Heptane was distilled before use. All solvents were filtered prior to use through a $0.45 \mu \mathrm{m}$ filter. HPLC-grade water was prepared in-house. Subsequently, this was on-line purified by a precolumn, containing a DOWEX cation exchanger and an ODS packing material, $(1: 1)$, in order to remove organic impurities and alkali metals from the water. This prohibited a significant decrease or, in the case of $100 \%$ water, even negative signals due to alkali metal interferences [17].

HPLC conditions for the copolymer analysis. All (co)polymer samples were dissolved in THF prior to analysis. In the case of the separation of poly(styrene-co-methyl acrylate) a linear gradient of 18 minutes was applied ranging from a mixture of $90 \%$ heptane, $9 \%$ dichloromethane and $1 \%$ methanol as the non-solvent to $100 \%$ (DCM $10 \%$ methanol) as the solvent (System I). The eluent flow rate was $0.5 \mathrm{~mL} / \mathrm{min}$ using a normal phase Chromsep $5 \mu \mathrm{m}$ silica cartridge column, $100 \times 3.0 \mathrm{~mm}$ (Chrompack, Middelburg, The Netherlands) at room temperature. In the case of the separation of poly(methyl acrylate-co-n-butyl acrylate) copolymers a linear gradient of 13 minutes was applied ranging from a mixture of $80 \% \mathrm{n}$-hexane, $18 \% \mathrm{DCM}$ and $2 \%$ methanol as the non-solvent to $15 \% \mathrm{n}$-hexane and $85 \%$ (DCM $+10 \%$ methanol) as the solvent (System II).

Polystyrene samples were isocratically eluted on a $5 \mu \mathrm{m}$ Lichrospher C 18 column, $100 \times 4 \mathrm{~mm}$ (Knauer, Berlin, FRG), at a flow rate of $0.6 \mathrm{~mL} / \mathrm{min}$; the eluents were THF and DCM with different percentages of $\mathrm{MeOH}$.

The Tracor LC/FID detector was equipped with a continuous quartz braid to transport the column effluent, which is sprayed on by a suitable applicator. Subsequently the braid is passed through a solvent removal zone and into the analytical and cleaning flames. Several stainless steel and home-made silica applicators of i.d. $50 \mu \mathrm{m}$ were used. The hydrogen and air flows were 130 and $400 \mathrm{~mL} / \mathrm{min}$, respectively, for the FID. The cleaning flame was fed by $\mathrm{H}_{2}$ and $\mathrm{O}_{2}$ flows of 600 and $300 \mathrm{~mL} / \mathrm{min}$, respectively. Small variations of the flows hardly affected the detector response. Base line correction (background subtraction) was always applied and the electronic filter was in the high position. Due to the heating of the two flames, an external vent was installed in order to maintain the FID housing block temperature at the desired setting. In this study, it turned out that the installation of the proper applicator with respect to the material and internal diameter was very important. Also a sufficiently large eluent flow rate must be mainteined in order to obtain a $100 \%$ application of the eluate on the transporting silica braid.

\section{Preparation of Copolymers}

Chemicals. Styrene (S), methyl acrylate (MA) and butyl acrylate (BA) (Merck) were distilled under nitrogen at reduced pressure, and subsequently stored at $277 \mathrm{~K}$ under nitrogen. The initiator potassium persulphate $\left(\mathrm{K}_{2} \mathrm{~S}_{2} \mathrm{O}_{8}\right)$ (Merck p.a.), the chain-transfer agent n.-dodecyl mercaptan (NDM) (Fluka for synthesis), the emulsifier sodium dodecylsulphate (SDS) (Fluka purity $\approx 99 \%$ ), and the solvent toluene (Merck p.a.), were used as received. The water was distilled twice and stored under nitrogen. The initiator $\alpha, \alpha^{\prime}$ azobis(isobutyronitrile) (AIBN) (Fluka p.a.) was recrystallized once from methanol.

Preparation of standard solution copolymers. The reference copolymers were synthesized by low-conversion solution copolymerization in toluene at $335 \mathrm{~K}$ for the poly(styrene-co-methyl acrylate) and at $323 \mathrm{~K}$ for the poly(methyl acrylate-co- $n$-butyl acrylate) copolymers. The total monomer concentration was $3 \mathrm{~mol} / \mathrm{L}$. The AIBN concentration was $8 \mathrm{mmol} / \mathrm{L}$. Conversion and monomer feed ratio were measured by means of gas chromatography using toluene as the internal standard. Conversion was always kept below $10 \mathrm{~mol} \%$ in order to prevent serious composition drift that would result in the formation of inhomogeneous copolymers. The solution copolymers were isolated and purified by pouring out the reaction mixture in to a 15 fold excess of cold $(273 \mathrm{~K})$ hexane. The final products were dried at $328 \mathrm{~K}$ in a vacuum oven for at least $6 \mathrm{~h}$ at $10^{-1}$ Torr and finally for $8 \mathrm{~h}$ at $10^{-5}$ Torr. The average copolymer chemical composition was determined by means of ${ }^{1} \mathrm{H}$ NMR.

In Table I the chemical composition determined by ${ }^{1} \mathrm{H}$ NMR and the molecular mass determined by GPC of the standard low conversion solution (homogeneous in chemical composition) copolymers and of the emulsion copolymers are given. Polystyrene standards were used for the calibration of the GPC.

Preparation of emulsion copolymers. The emulsion copolymers were prepared under nitrogen in a $1.3 \mathrm{~L}$ stainless steel reactor thermostated at $323 \mathrm{~K}$ in the case of styrenemethyl acrylate and at $308 \mathrm{~K}$ in the case of methyl acrylate - butyl acrylate. SDS was used as emulsifier, $\mathrm{K}_{2} \mathrm{~S}_{2} \mathrm{O}_{8}$ as initiator and NDM as chain transfer agent. The amounts of the different chemicals used are given in Table II. Latices were purified by removing SDS and unreacted $\mathrm{K}_{2} \mathrm{~S}_{2} \mathrm{O}_{8}$, monomers and NDM by means of dialysis.

\section{Results and Discussion}

In earlier investigations it was shown that poly(styrene-comethyl acrylate) copolymers can be separated according to their chemical composition on both reversed phase and normal phase columns $[4,11]$. From this work it was concluded that normal phase columns gave a slightly better resolution in the styrene rich range, whereas for reversed 
Table I List of reference copolymers, prepared by solution polymerisation, compositions and weight average molecular weights.

\begin{tabular}{|cc|}
\hline $\begin{array}{c}\text { poly(styrene-co-methyl acrylate) } \\
\text { mol\% styrene }\end{array}$ & $\begin{array}{c}\text { copolymers } \\
\text { molecular weight }(\mathrm{kg} / \mathrm{mol})\end{array}$ \\
\hline 100 & 43 \\
83 & 190 \\
76 & 66 \\
57 & 74 \\
46 & 75 \\
29 & 58 \\
12 & 110 \\
0 & 111 \\
\hline poly(methyl acrylate-co- $n$-butyl acrylate) copolymers \\
mol\% butyl acrylate & molecular weight $(\mathrm{kg} / \mathrm{mol})$ \\
\hline 100 & 256 \\
90 & 594 \\
77 & 557 \\
70 & 589 \\
52 & 464 \\
42 & 432 \\
21 & 339 \\
9 & 389 \\
0 & 111 \\
\hline
\end{tabular}

Table II The amounts of chemicals used for the preparation of the emulsion copolymers PSMA and PMABA.

\begin{tabular}{|lcc|}
\hline & $\begin{array}{c}\text { PSMA } \\
(\mathrm{g})\end{array}$ & $\begin{array}{c}\text { PMABA } \\
(\mathrm{g})\end{array}$ \\
\hline water & 600.2 & 723.5 \\
styrene & 34.50 & - \\
methyl acrylate & 85.50 & 14.59 \\
butyl acrylate & - & 21.55 \\
$\mathrm{NDM}$ & 2.01 & 0.40 \\
$\mathrm{NLS}$ & 2.01 & 2.00 \\
$\mathrm{~K}_{2} \mathrm{~S}_{2} \mathrm{O}_{8}$ & 0.20 & 0.20 \\
\hline
\end{tabular}

phase columns a slightly better performance in the methyl acrylate rich range was observed. In this study it was found that the separation of methacrylate rich copolymers on reversed phase columns with mixtures of THF, MeOH and water as the eluent resulted in a severe decrease of the FID response.

In order to calculate the response of the FID, constant amounts of a standard solution of polystyrene were repeatedly injected under isocratic conditions using THF as the eluent. The variation in the resulting peak areas was less than $4 \%$ with a response of circa $3.8 \times 10^{-5}$ coulomb/g carbon, which is in satisfying agreement with the literature values for the moving wire FID [17]. However, it has to be noticed that this response is about three orders of magnitude lower than the value of about $10^{-2}$ coulomb/g carbon normally observed for $\mathrm{C}$ and $\mathrm{H}$-containing compounds in gas-chromatography with FID. The response and reproducibility were shown to be independent of the block (i.e. FID housing) temperature in the range of $80-200^{\circ} \mathrm{C}$.

Under the same experimental conditions at a block temperature of $80^{\circ} \mathrm{C}$ and using a silica applicator of $50 \mu \mathrm{m}$ i.d., the addition of polar solvents $\left(\mathrm{H}_{2} \mathrm{O}\right.$ or methanol) to the isocratic elution system resulted in a large decrease in the FID response. As an example, the addition of $5 \% \mathrm{v} / \mathrm{v}$ of $\mathrm{MeOH}$ to the DCM eluent resulted in a $35 \%$ decrease of the original response. A similar signal decrease was observed for polyacrylic acid samples eluted on the Lichrospher column with methanol as the eluent, containing different amounts of water.

From these experiments it can be concluded that the addition of polar solvents like water and methanol decreases the response of the FID for the (co)polymer samples. Therefore, to obtain reliable results the amounts of theser solvents in the eluent should be kept constant and as low as possible. Since, water and methanol are very often used in reversedphase chromatography this limits the applicability of the technique in combination with FID.

\section{Poly(styrene-co-methyl acrylate), PSMA Copolymers}

A number of PSMA copolymer samples were analyzed under the experimental conditions given under system I in the experimental section, with a normal phase column. The composition and concentrations of the reference (co)polymers are given in Table III (1A and 1B).

In Figure 1 two typical chromatograms are given representing a separation of 3 copolymers and both the homopolymers of methyl acrylate and styrene. In Figure 1a the chromatogram obtained at $260 \mathrm{~nm}$ UV detection exhibits a response decrease with decreasing styrene content, whereas the chromatogram obtained with FID detection, given in Figure 1b, shows all (co)polymer peaks including the almost non-UV-absorbing PMA peak. Also from these data the calibration curve of the retention time versus the chemical composition of the copolymers was plotted (Figure 2).

In Figure 3 the FID response as peak areas coulomb is given as a function of the injected copolymer mass. From this

Table III Composition of the standard test solutions of the reference copolymers.

\begin{tabular}{|c|c|c|c|}
\hline \multicolumn{2}{|c|}{$1 \mathrm{~A}$} & \multicolumn{2}{|c|}{$1 \mathrm{~B}$} \\
\hline$\%$ styrene & $\begin{array}{c}\text { concentration } \\
(g / L)\end{array}$ & $\%$ styrene & $\begin{array}{c}\text { concentration } \\
(\mathrm{g} / \mathrm{L})\end{array}$ \\
\hline 100 & 0.2 & 100 & 0.22 \\
\hline 83 & 0.18 & 76 & 0.16 \\
\hline 57 & 0.18 & 46 & 0.16 \\
\hline 29 & 0.19 & 12 & 0.16 \\
\hline 0 & 0.18 & 0 & 0.25 \\
\hline \multicolumn{4}{|c|}{ no. 2 poly(methyl acrylate-co- $n$-butyl acrylate) copolymers } \\
\hline \multicolumn{2}{|c|}{$2 \mathrm{~A}$} & \multicolumn{2}{|c|}{$2 \mathrm{~B}$} \\
\hline $\begin{array}{l}\% \text { butyl } \\
\text { acrylate }\end{array}$ & $\begin{array}{l}\text { concentration } \\
(g / L)\end{array}$ & $\begin{array}{l}\% \text { butyl } \\
\text { acrylate }\end{array}$ & $\begin{array}{c}\text { concentration } \\
(\mathrm{g} / \mathrm{L})\end{array}$ \\
\hline 100 & 2.1 & 90 & 1.4 \\
\hline 77 & 1.8 & 70 & 1.9 \\
\hline 52 & 1.7 & 42 & 2.0 \\
\hline 21 & 1.7 & 9 & 2.9 \\
\hline 0 & 2.2 & - & - \\
\hline
\end{tabular}




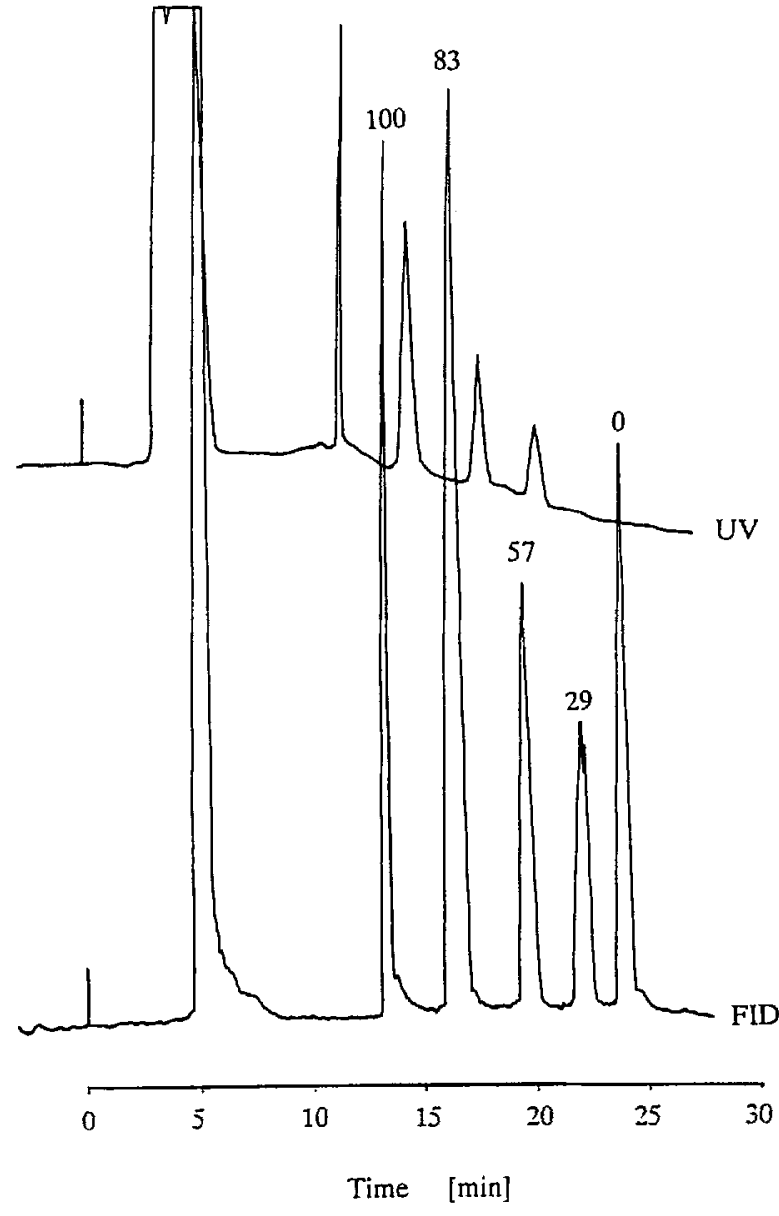

Figure 1

HPLC chromatograms of a mixture of 5 reference PSMA (co)polymers with various compositions. $75 \mu$ injected of solution $1 \mathrm{~A}$ in Table III; column: Chromsphere Si; eluent A:n-heptane; eluent B: DCM $+10 \%$ methanol; Gradient $10 \% \rightarrow 100 \% \mathrm{~B}, 18 \mathrm{~min}$; flow $=0.6 \mathrm{~mL} / \mathrm{min}$; Temperature ambient.

$\mathrm{UV}=260 \mathrm{~nm} ; \mathrm{FID}$, block temp. $=120^{\circ} \mathrm{C}$, att. $=20$. The copolymer compositions, as $\mathrm{mol} \%$ styrene are indicated in the figure.

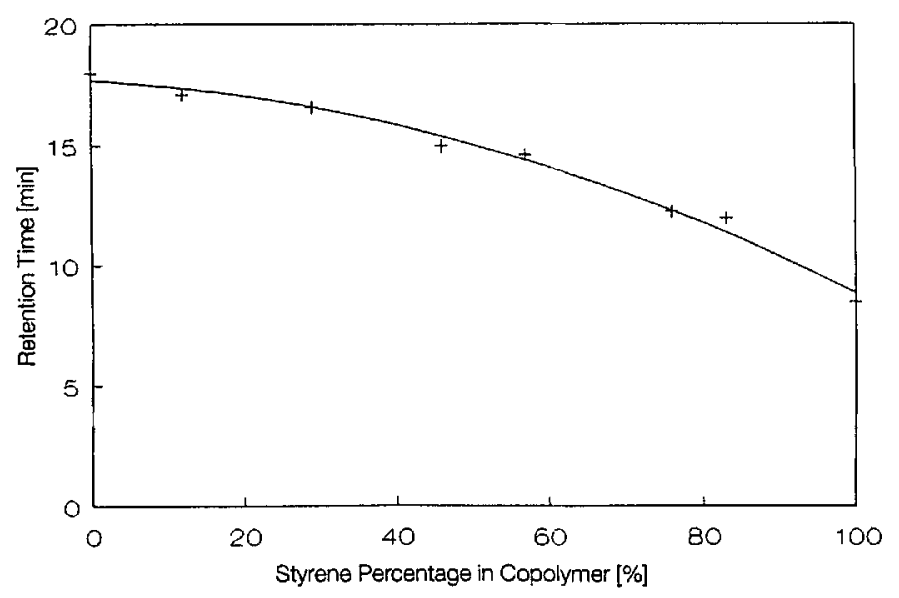

Figure 2

Retention time as a function of the fraction of styrene in a PSMA copolymer. Conditions: $75 \mu \mathrm{l}$ injected of solutions $1 \mathrm{~A}$ and $1 \mathrm{~B}$ in Table III; column: Chromsphere Si; eluent A: n-heptane; eluent B: DCM + $10 \%$ methanol; Gradient $10 \% \rightarrow 100 \%$ B, $18 \mathrm{~min}$; flow $=0.6 \mathrm{~mL} / \mathrm{min}$; Temperature ambient.

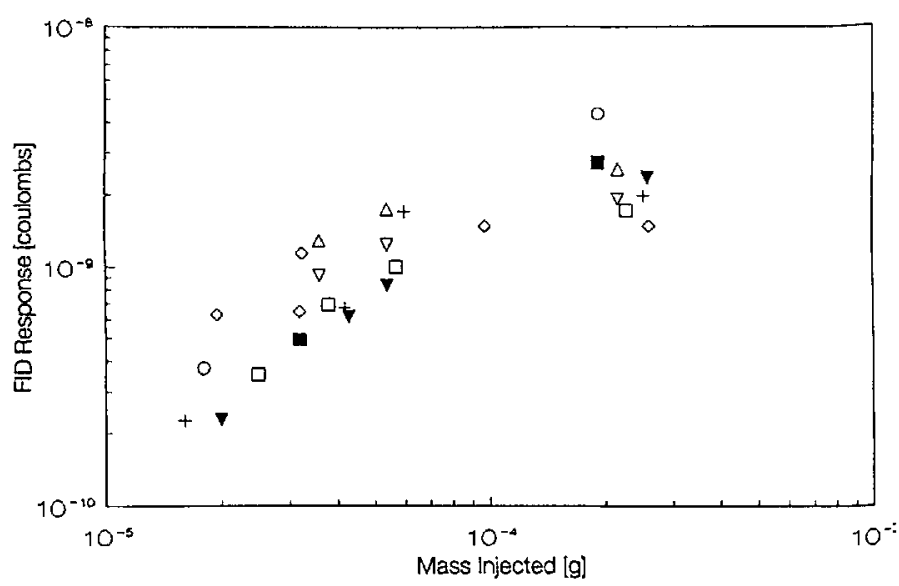

Figure 3

FID response in coulomb as a function of the injected mass of various styrene-methyl acrylate copolymers. Conditions: different injection volumes of solutions $1 \mathrm{~A}$ and $1 \mathrm{~B}$ in Table III; column: Chromsphere $\mathrm{Si}$; eluent A: n-heptane; eluent B: DCM $+10 \%$ methanol; Gradient $10 \% \rightarrow 100 \% \mathrm{~B}, 18 \mathrm{~min} ;$ flow $=0.6 \mathrm{~mL} / \mathrm{min}$; Temperature ambient. Block temp. $=120^{\circ} \mathrm{C}$, att. $=20$.

$(+)=\mathrm{PS} ; \Delta=83 \% ; \mathrm{O}=76 \% \mathrm{~S} ; \nabla=57 \% \mathrm{~S} ; 0=92 \% \mathrm{~S} ; \square=29 \% \mathrm{~S}$ $\mathbf{Q}=12 \% \mathrm{~S}, \boldsymbol{\nabla}=$ PMA.

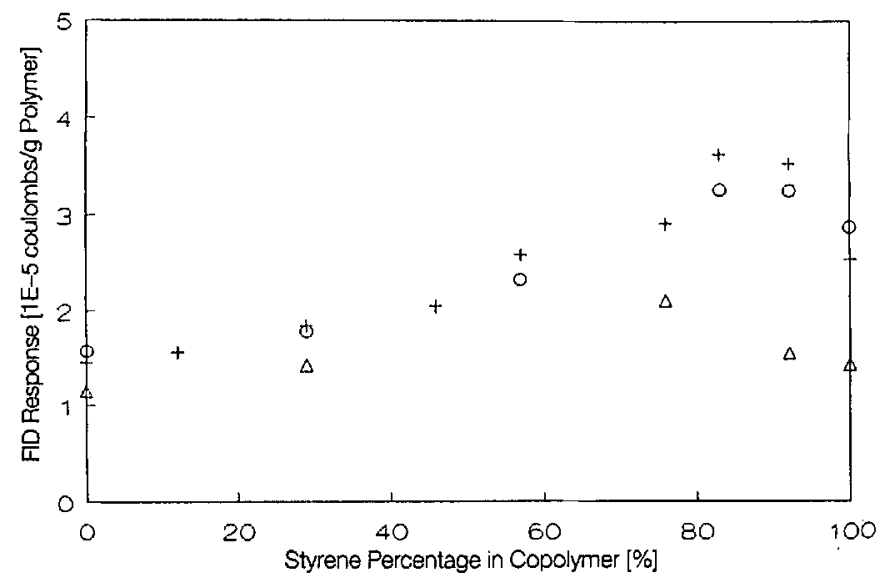

Figure 4

FID response in coulomb/g PSMA (co)polymer as a function of the copolymer chemical composition given in mol\% styrene. Conditions: different injection volumes of solutions $1 \mathrm{~A}$ and $1 \mathrm{~B}$ in Table III, column: Chromsphere Si; eluent A: n-heptane; eluent B: DCM $+10 \%$ methanol; Gradient: $10 \% \rightarrow 100 \% \mathrm{~B}, 18 \mathrm{~min}$; flow $=0.6 \mathrm{~mL} / \mathrm{min}$; Temperature ambient. Block temp. $=120^{\circ} \mathrm{C}$, att. $=20$. $\Delta=5 \mu \mathrm{l} ;+=10 \mu \mathrm{l} ; 0=30 \mu \mathrm{l}$.

figure it can be concluded that below circa $0.07 \mathrm{mg}$ the response of a specific component is linearly dependent on the injected mass. Furthermore the absolute response of the FID depends on the copolymer composition. The observation in gas chromatography that the response of the FID depends on the carbon content of a specific component and also on its chemical structure is confirmed to be valid for the larger molecules involved in this study.

Figure 4 represents the response of some PSMA copolymers as a function of the styrene content. The plot of the relative reponse as a function of percentage styrene exhibits a maximum at approximately $85 \%$ styrene. This complicates 
the accurate calculation of the CCD from an HPLC/FID chromatogram.

It can be concluded that for accurate quantitative measurements it is necessary for both UV- and flame ionisation detection modes to be carefully calibrated. However, the detection of non- and low UV-absorbing copolymer samples requires a detector whose operating principle is not based upon UV-absorption, e.g. a transport mechanism in combination with an FID (present case) or an evaporative light-scattering detector.

As an example of this in Figure 5 the UV $(260 \mathrm{~nm})$ and the FID chromatograms of a bimodal emulsion copolymer are given. In contrast to the UV chromatogram, which does not reveal the polymethyl acrylate peak, the FID chromatogram shows the expected bimodality.

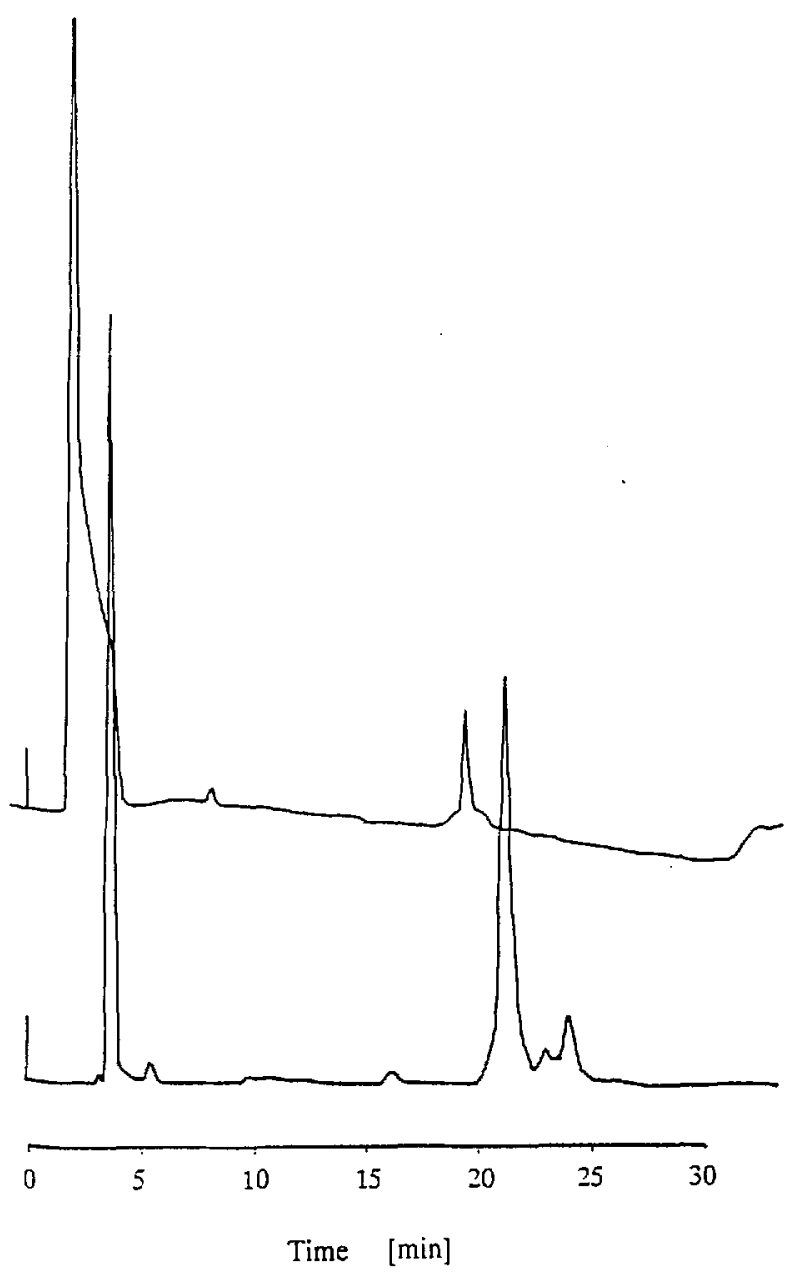

UV

Figure 5

HPLC chromatogram of a high conversion ( $96 \mathrm{wt} \%$ ) emulsion copolymer of styrene and methyl acrylate of an average chemical composition of $25 \%$ styrene. Column: Chromosphere Si;eluent A: n-heptane, eluent B: DCM $+10 \%$ methanol; gradient $10 \% \rightarrow 100 \%, \mathrm{~B}, 18 \mathrm{~min}$, $0.6 \mathrm{ml} / \mathrm{min}$; temperature: ambient. $60 \mu \mathrm{L}$ injected of a copolymer solution in THF $(20 \mathrm{mg} / 10 \mathrm{~mL})$.

$260 \mathrm{~nm}$, UV detection; moving wire FID, block temp. $=120^{\circ} \mathrm{C}$, att. $=$ 50.

\section{Poly(methyl acrylate-co- $n$-butyl acrylate), PMABA Copolymers}

A number of PMABA samples were analyzed under the experimental conditions given under system II in the experimental section. The composition and concentrations of the reference (co)polymers are given in Table III, $2 \mathrm{~A}$ and $2 \mathrm{~B}$.

In Figure 6 the separation of a mixture of 3 methyl acrylatebutyl acrylate copolymers and the two homopolymers, is given using UV detection at $235 \mathrm{~nm}$ and the FID. Relatively strong FID responses, compared to the UV signals, were observed. Moreover, the FID response is not influenced by the gradient eluent composition, facilitating quantitative calculations.

The reference (co)polymers were prepared by means of low-conversion solution (co)polymerization with AIBN as the initiator. Therefore, the copolymers formed contain $\mathrm{C}$ $\equiv \mathrm{N}$ end groups, which can by detected at $235 \mathrm{~nm}$. This

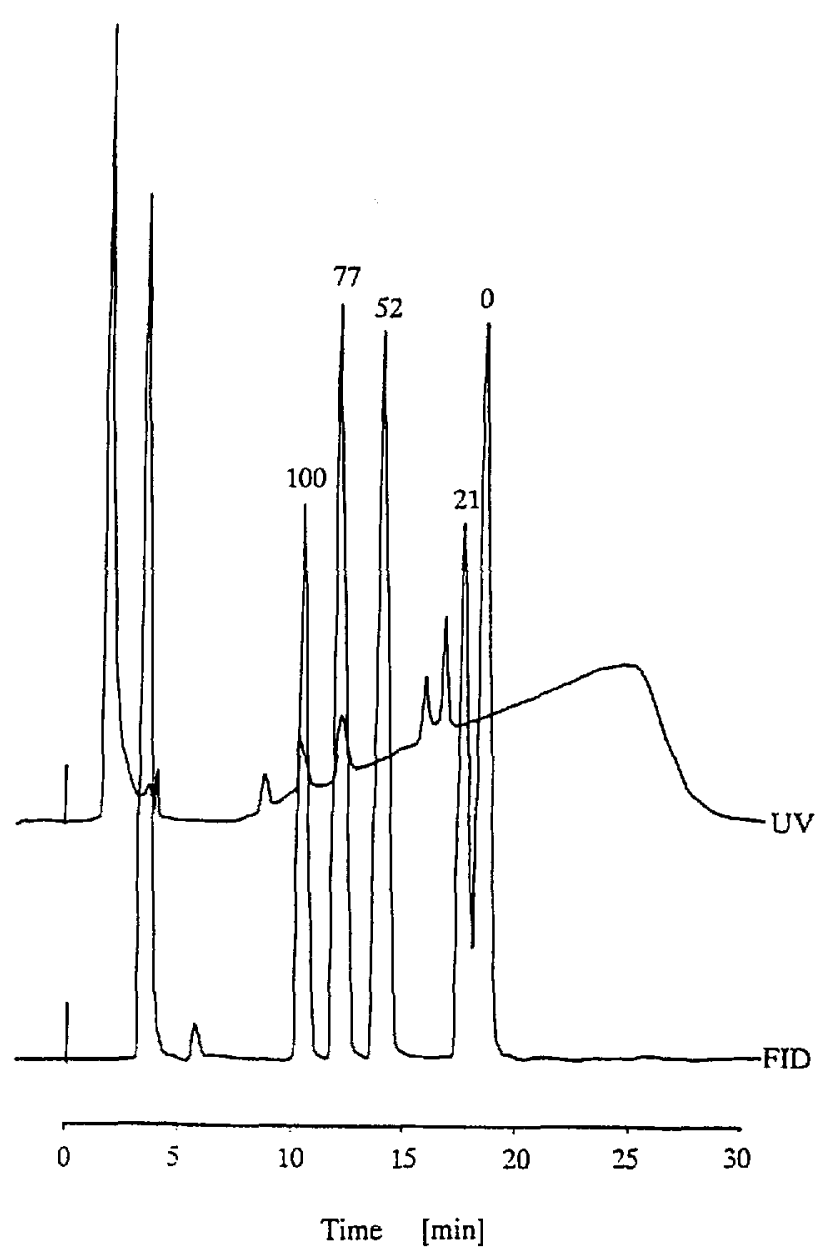

Figure 6

HPLC chromatogram of a mixture of 5 reference (co)polymers of methyl acrylate and butyl acrylate with various compositions. $20 \mu \mathrm{l}$ injected of solution 2A in Table III; column: Chromsphere Si; eluent A: n-heptane; eluent B:DCM $+10 \%$ methanol; Gradient $20 \% \rightarrow 85 \%$ B, $13 \mathrm{~min}$; Temperature ambient. UV detection $235 \mathrm{~nm}$; FID, $50 \mu \mathrm{m}$ i.d. silica applicator, block temp. $=120^{\circ} \mathrm{C}$, Att. $=50$. 


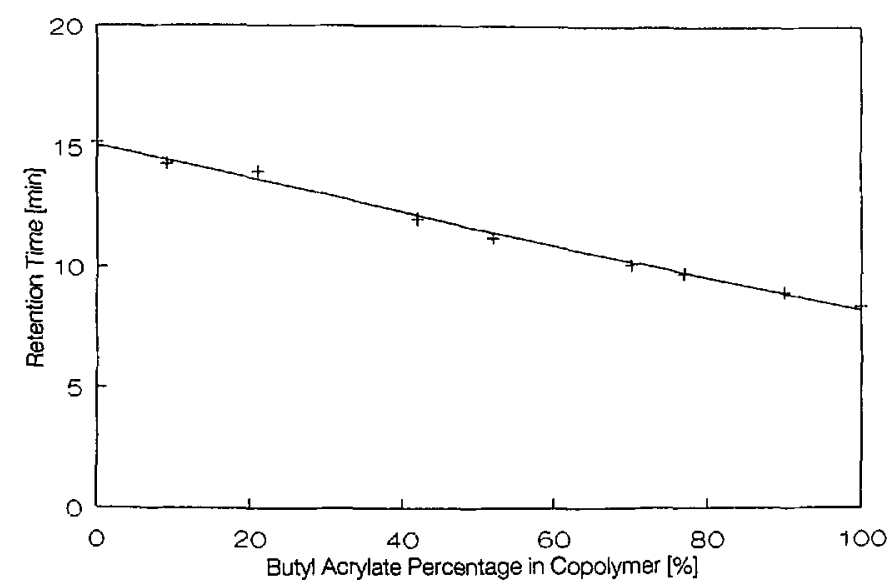

Figure 7

Retention time as a function of the fraction of butyl acrylate units in the copolymer. Conditions: $20 \mu \mathrm{l}$ injected of solutions $2 \mathrm{~A}$ and $2 \mathrm{~B}$ in Table III; column: Chromsphere $\mathrm{Si}$; eluent $\mathrm{A}$ : n-heptane; eluent B: DCM $+10 \%$ methanol; Gradient $20 \% \rightarrow 85 \%$ B, 13 min; Temperature ambient.

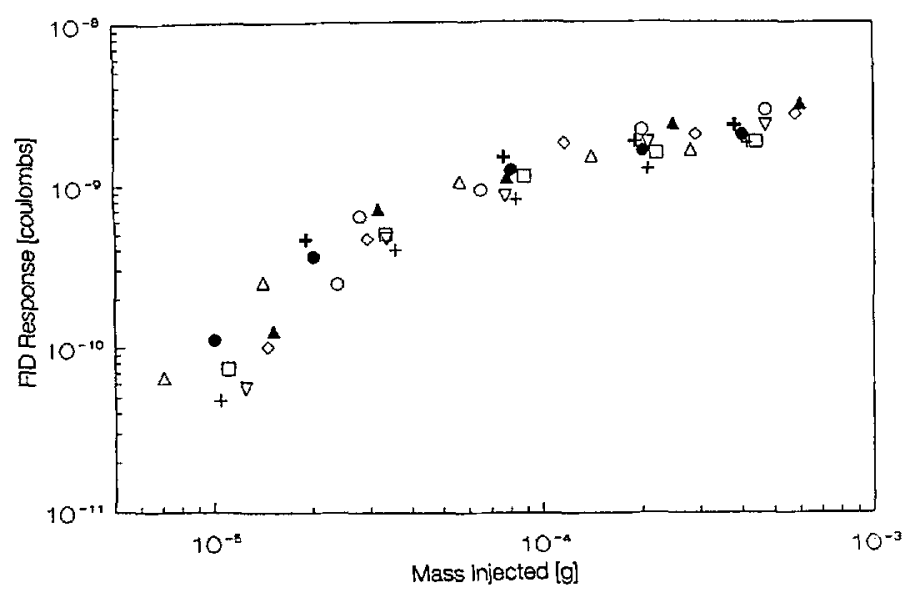

Figure 8

FID response in coulomb as a function the injected mass of various methyl acrylate - co-n-butyl acrylate (co)polymers. $+=\mathrm{PB}, \Delta=90 \%$ $\mathrm{BA}, 0=77 \% \mathrm{BA},+=70 \% \mathrm{BA}, \boldsymbol{\Delta}=52 \% \mathrm{BA}, \quad=42 \% \mathrm{BA}, \nabla=21 \%$ $\mathrm{BA}, \vartheta=9 \% \mathrm{BA}, \square=\mathrm{PMA}$.

Conditions: different injection volumes of solutions $2 A$ and $2 B$ in Table III; column: Chromsphere Si; eluent A: n-heptane; eluent B: $\mathrm{DCM}+10 \%$ methanol; Gradient $20 \% \rightarrow 85 \% \mathrm{~B}, 13 \mathrm{~min}$; Temperature ambient. FID, $50 \mu \mathrm{m}$ i.d. silica applicator, block temp. $=120^{\circ} \mathrm{C}$

results in unwanted molecular weight dependence of the signal. In contrast to the solution copolymers, the emulsion copolymers, which are generally prepared with persulphate initiators, do not exhibit any significant UV absorption.

Various separations of the PMABA copolymer samples were performed at different injection volumes. From the chromatograms obtained the FID response of all polymer peaks and the retention data were determined.

In Figure 7 the retention time of the copolymers as a function of \% butyl acrylate is given. Figure 8 shows the copolymer FID response in coulombs as a function of injected mass of the individual (co)polymers.

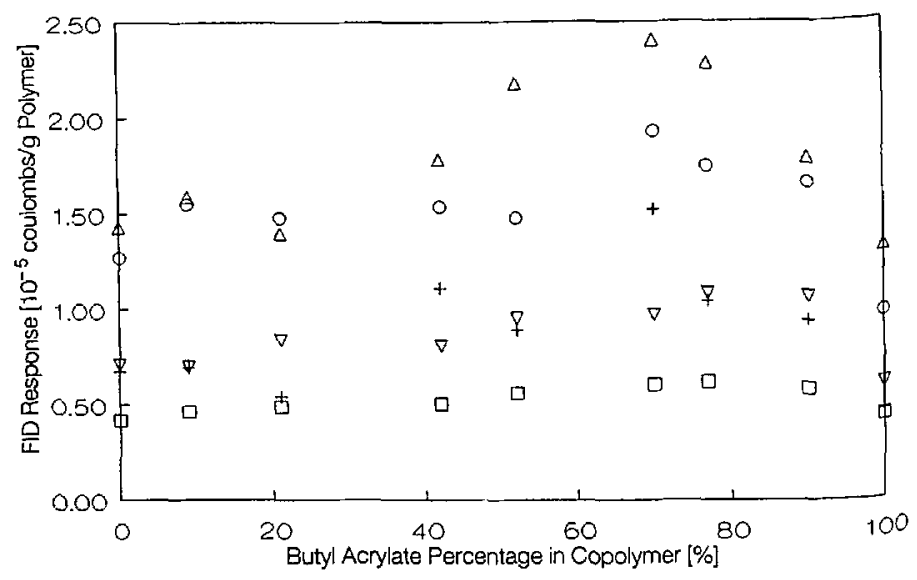

Figure 9

FID response in coulomb/g PMABA polymer as a function of the copolymer chemical composition given in mol\% butyl acrylate at several injection volumes: $+=5 \mu \mathrm{l}, \Delta=20 \mu \mathrm{l}, \mathrm{o}=40 \mu \mathrm{l}, \nabla=100 \mu \mathrm{l}, \square$ $=200 \mu \mathrm{l}$.

Conditions: different injection volumes of solutions $2 \mathrm{~A}$ and $2 \mathrm{~B}$ in Table III; column: Chromsphere Si; eluent A: n-heptane; eluent $B$ $\mathrm{DCM}+10 \%$ methanol; Gradient $20 \% \rightarrow 85 \%$ B, 13 min; Temperature ambient. FID, $50 \mu \mathrm{m}$ i.d. silica applicator, block temp. $=120^{\circ} \mathrm{C}$.

From this it can be concluded that the response as a function of the injected mass of the copolymer is nearly linear up to $0.1 \mathrm{mg}$. Moreover, it is clear that the response also depends on the chemical composition of a specific copolymer; a similar behaviour to that observed for PSMA copolymers. The FID response in coulombs/g as a function of the $\%$ butyl acrylate at different injected masses of the copolymers is shown in Figure 9. This plot exhibits a similar behaviour to that observed for the poly(styrene-co-methyl acrylate) copolymers: a maximum in the response in this plot also appeared. The highest response was determined at an injection volume of $20 \mu \mathrm{L}$ of solution 2 .

In Figure 10 a typical chromatogram, recorded under optimal conditions, is shown of poly (methyl acrylate-co-n-butyl acrylate) copolymer prepared in emulsion. The chromatogram obtained with $235 \mathrm{~nm}$ UV detection does not reveal the copolymer, since no AIBN but $\mathrm{K}_{2} \mathrm{~S}_{2} \mathrm{O}_{8}$ initiator has been used for the emulsion copolymer preparation. The FID detector, however, detects both these types of copolymers. Assuming a FID response independent on chemical composition and a linear dependence of the reponse on (co)polymer mass, a chemical composition distribution (CCD) has been calculated. In Figure 11 the experimentally determined CCD is compared with a model calculation of the $\mathrm{CCD}$. The model CCD has been calculated using the simulation program "SIEMCO" (Simulation Emulsion Copolymerization). This model takes into account the effect of composition drift on the copolymer composition (conversion heterogeneity) as well as the instantaneous (= statistical) heterogeneity $[7,20]$. The average chemical composition of the emulsion copolymer is $55 \%$ butyl acrylate. The CCD predicted by the model and the experimentally determined CCD reveal the occurrence of composition drift during preparation, as indicated by the asymmetrical shape of the peaks. 


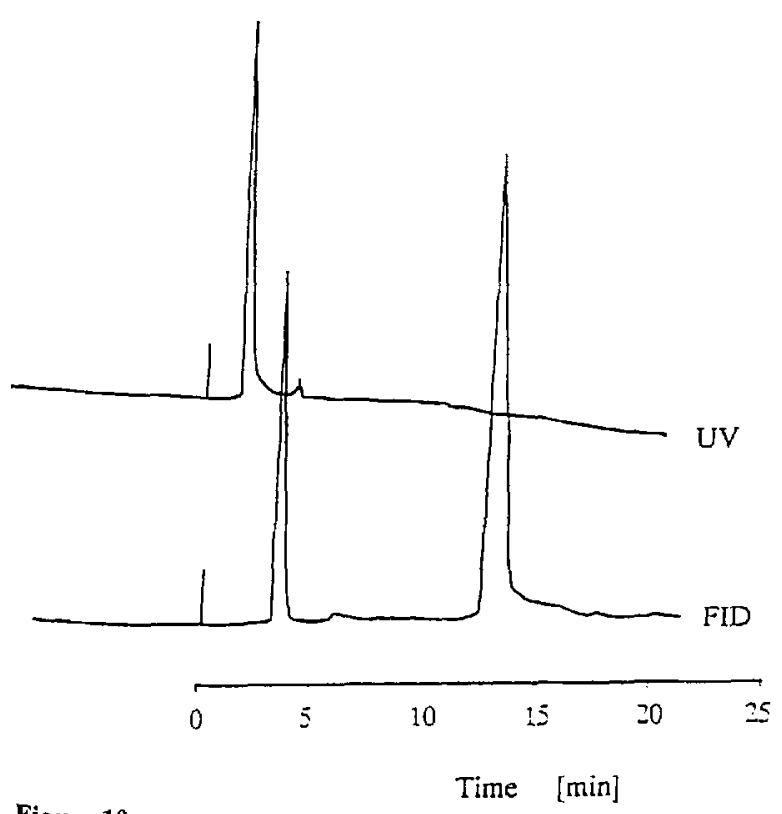

Figure 10

HPLC chromatogram of a high conversion (92 wt\%) emulsion copolymer of methyl acrylate and $n$-butyl acrylate having an average chemical composition of $55 \mathrm{~mol} \% n$-butyl acrylate, prepared at an initial monomer ratio of $(\mathrm{MA} / \mathrm{BA})_{0}=1(\mathrm{~mol} / \mathrm{mol})$ and an initial monomer to water ratio of $0.05 \mathrm{~g} / \mathrm{g} . \mathrm{M}_{\psi}$ of the sample (determined by SEC) $800000 \mathrm{~g} / \mathrm{mol}$. Column: Chromosphere Si; eluent A: n-heptane; eluent B: DCM $+10 \%$ methanol; gradient $10 \% \rightarrow 100 \%, B, 18 \mathrm{~min}$, $0.6 \mathrm{ml} / \mathrm{min}$; temperature: ambient. $25 \mu \mathrm{L}$ injected of a copolymer solution in THF $(22 \mathrm{mg} / 10 \mathrm{~mL}) .235 \mathrm{~nm}$ UV detection; moving wire FID, $50 \mu \mathrm{m}$ i.d. silica applicator, att. 50, block temp. $=250^{\circ} \mathrm{C}$.

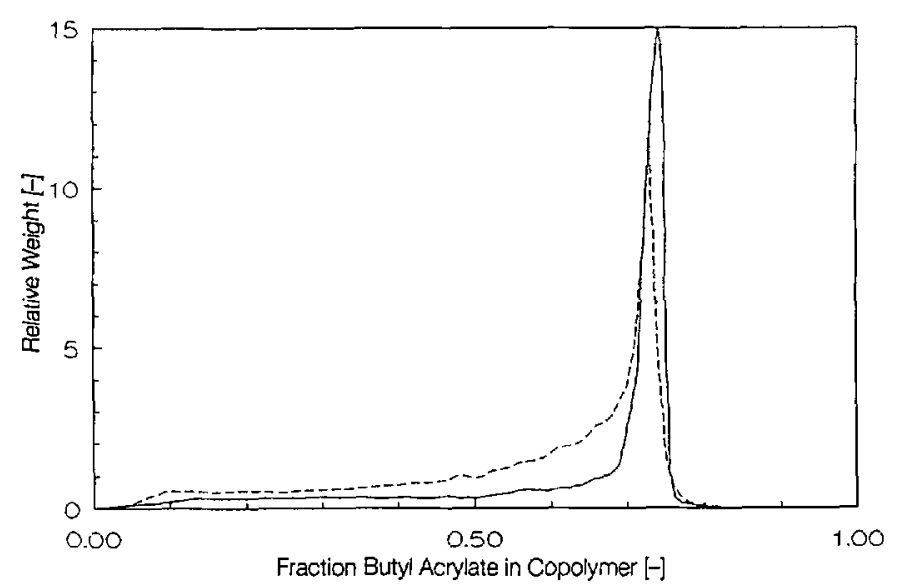

Figure 11

CCD of the emulsion copolymer of Figure 10.

Dashed line: model calculation plot on the basis of $\mathrm{M}_{w}=800000 \mathrm{~g} / \mathrm{mol}$; full line: experimentally determined plot by means of HPLC/FID.

\section{Conclusions}

UV detection in the HPLC separation of some types and composition ranges of copolymers has its limitations due to the lack of sufficiently strong UV chromophores and/or the concentration of those substances. In these cases the detection of the substances by a moving wire FID is an attractive alternative as has been shown in this study.

The FID response is decreased by cosolvents like water and methanol in the eluent. The FID response depends on the chemical composition of a specific copolymer, which is also the case for UV-detection. For accurate quantitative measurements careful calibration is therefore necessary for both FID and UV-detection. For some specific (co)polymers the FID response is superior to the response of the UV detector.

\section{Acknowledgement}

The authors thank Ir. R. Sparidans for carrying out some preliminary experiments with the moving wire FID, Ir. R. Mommers for preparing the PMABA copolymers, Mr. W. Kingma for the SEC analyses and Mrs. D. Tjallema for the accurate handling of the manuscript.

\section{References}

[1] F. B. Padley, J. Chromatogr., 39, 37 (1969).

[2] S. Teramachi, A. Hasegawa, N. Uchiyama, J. Polym. Sci., Polym. Lett. Ed., 22, 71 (1984).

[3] J. C. J. F. Tacx, J. L. Ammerdorffer, A. L. German, Polymer, 29, 2087 (1988).

[4] S. Teramachi, A. Hasegawa, Y. Shima, M. Akatsuka, M. Nakajima, Macromolecules, 12, 992 (1979).

[5] S. Teramachi, A. Hasegawa, S. Yoshida, Macromolecules, 16,542 (1983).

[6] H. Inagaki, H. Malsuda, F. Kamiyama, Macromolecules, 1, 520 (1968).

[7] G. H. J. van Doremaele, A. M. van Herk, A. L. German, Makromol. Chem., Macromol. Symp., 35, 36 (1990).

[8] G. Glöckner, "Analysis of Compositional and Structural Heterogeneities of Polymers by Non-Exclusion Chromatography", "Advances in Polym. Sci.", Springer-Verlag, Berlin, 79, 159(1988).

[9] S. Mori, Anal. Chem., 60, 1125 (1988).

[10] S. Mori, J. Chromatogr., 507, 473 (1990).

[11] R.W. Sparidans, H. A. Claessens, G. H.J. van Doremaele, A. M. van Herk, J. Chromatogr., 508, 319 (1990).

[12] J. L. Robinson, R. Macrae, J. Chromatogr., 303, 386 (1984).

[13] J. L. Robinson, M. Tsimidou, R. Macrae, J. Chromatogr., 324, 35 (1985).

[14] L. E. Oppenheimer, T. H. Mourey, J. Chromatogr., 323,297 (1985).

[15] M. Righezza, G. Guiochon, J. Liq. Chrom., 22, 2709 (1988).

[16] K. Aitzetmuiller, J. Chrom. Sci., 13, 454 (1975).

[17] J. B. Dixon, Chimia, 38, 83 (1984).

[18] R. L. Veazey, JAOCS, 63, 1043 (1986).

[19] G. H.J. van Doremaele, Ph.D. Thesis, "Model Prediction, Experimental Determination, and Control of Emulsion Copolymer Microstruclure", Eindhoven, University of Technology, The Netherlands, 1990.

[20] W. H. Stockmayer, J. Chem. Phys., 13, 199 (1945).

Received: Jan 7,1991 Revised manuscript received: Feb 27, 1991 Accepted:Mai 5, 1991 B 